Article

\title{
Microstructural Changes in Suspension Plasma-Sprayed TBCs Deposited on Complex Geometry Substrates
}

\author{
Wellington Uczak de Goes*(D), Nicolaie Markocsan and Mohit Gupta \\ Department of Engineering Science, University West, 46153 Trollhättan, Sweden; \\ nicolaie.markocsan@hv.se (N.M.); mohit-kumar.gupta@hv.se (M.G.) \\ * Correspondence: wellington.uczak-de-goes@hv.se
}

Received: 11 June 2020; Accepted: 17 July 2020; Published: 20 July 2020

\begin{abstract}
Thermal barrier coatings (TBCs) are considered a promising solution for improving the efficiency of internal combustion engines. Among the thermal spray processes, the relatively newly developed suspension plasma spray (SPS) is an attractive candidate due to its unique microstructural features that have already demonstrated increased performance in gas turbine applications. To achieve these features, thermal spray conditions play an essential role. In specific uses, such as piston of diesel engines, parameters as spray angle and spray distance pose challenges to keep them constant during the whole spray process due to the complex geometry of the piston. To understand the effect of the spray distance and spray angle, a comprehensive investigation of the produced thermal spray microstructure on the piston geometry was conducted. Flat and complex geometry surfaces were coated using the same plasma parameters while the spray angle and distance were changed. Characterization was performed using scanning electron microscopy (SEM) combined with the image analysis technique to perceive the variation of the thickness and microstructures features such as pores, cracks, column density, and column orientation. The results showed that the changes in spray angles and spray distances due to the complex shape of the substrate have a significant influence on the microstructure and thermal properties (thermal conductivity and thermal effusivity) of the coatings. The thermal conductivity and thermal effusivity were calculated by modeling for the different regions of the piston and measured by laser flash analysis combined with modeling for the flat-surfaced coupon. It was shown that the modeling approach is an effective tool to predict the thermal properties and thus to understand the influence of the parameters on the coating properties. Connecting the observations of the work on the microstructural and thermal properties, the complex geometry's influence on the produced coatings could be diminished by tailoring the process and generating the most desirable TBC for the internal combustion engines in future applications.
\end{abstract}

Keywords: thermal barrier coatings; suspension plasma spraying; complex geometry substrate; internal combustion engines; object-oriented finite element (OOF2)

\section{Introduction}

Thermal barrier coatings (TBCs) are widely employed on gas turbine engines to achieve higher efficiency due to the insulation properties of the coatings allowing higher combustion temperatures $[1,2]$. This feature made the TBCs interesting for other applications such as internal combustion engines used in the automotive industry [3-9].

The atmospheric plasma spray (APS) is one of the most used thermal spraying techniques in which liquid/molten droplets of a powder feedstock impact the surface of the part to be coated and solidify in structures identified as splats. After the powder particle enters the plasma plume, the spray distance 
and the spray angle exhibit an effect on the droplet temperature and velocity when impacting the substrate [10-12]. At higher spray distance, the droplet would be exposed to the environment longer, resulting in cooler particles; these colder particles can result in higher porosity coatings, as shown previously by Gupta et al. [11]. The different spray angles affect the particle deformation dynamics. With off normal spray angles, there is a lower normal impact velocity leading to a lower deposition efficiency, as presented by Montavon et al. [10].

The suspension plasma spray (SPS) is an emerging thermal spray process that can produce coatings with superior engine efficiency when applied on the pistons of a light-duty diesel engine [8,9]. In the SPS process, a combination of submicron or nano-sized powders (solute) and a solvent, usually water or alcohol is used as feedstock. This suspension feedstock is injected into the plasma plume and with atomization forms fine droplets. Because of the high temperatures, the solvent evaporates, and the particles partially or fully melt [13]. Following this, the droplets impact the substrate producing a nanostructured microstructure [14]. The coating formation in SPS is controlled by the momentum of the droplet and the plasma drag. The small droplets $(<1 \mu \mathrm{m})$ with a low momentum when following the plasma streamline over the substrate surface are mostly deposited at shallow angles on the asperities of the surface and thus causing a shadowing effect [15]. Due to the shadowing effect, the typical columnar microstructure is formed [16].

Due to the smaller size of the droplet in SPS, increased influence of the spray distance and spray angle can be noticed as compared to APS, affecting the droplet's temperature and velocity at impact more significantly [16-19]. The influence of spray distance is the same way as in the APS coating, and the higher droplet temperature when shorter spray distance was used led, as shown by Pourang et al. [19], to a higher deposition rate. The spray angle influences the particle trajectory and the shallow angle deposition (typical for SPS), affecting, in turn, the microstructure and columns formation. As shown by Ganvir et al. [20], different microstructures can be formed due to changes in the spray angle that led to deviations in the angle of impact of the droplet.

The microstructure and thermal properties of TBCs are dictated by several spraying parameters. As frequently observed, the coating's microstructure and thermal properties sprayed on coupons cannot be reproduced on real parts due to the difficulties replicating similar deposition conditions $[20,21]$. The substrate shape interferes with the spraying due to complex shapes, particularly in the SPS coating. This is expected because it influences the plasma drag that impacts the trajectory and velocity of the droplet. Bernard et al. [21] investigated SPS coatings, which were sprayed on a real turbine blade where the spray distance and spray angles could not be kept uniform due to the geometry of the part. The importance of the spray distance and spray angle was confirmed due to the massive variation in the coating microstructure and thickness, from a vertically cracked microstructure on the convex area of the blade to a columnar microstructure with different thicknesses along the different regions of the blade's concave area [21].

Caio and Moreau [22] also illustrated the challenges of SPS coatings deposition on complex shapes. Three different shapes with different roughness were sprayed, and different microstructures were observed, from thicker dense coatings in the center of the substrate to thin columnar coatings in the edges [22]. This variation was due to the substrate shape characteristics, e.g., with different curvature radius, there were effects on the deposition rate and the column growth. This effect can result in the droplet to rebound being either resprayed or be expelled, resulting in microstructural changes in the final coating [23-25].

The motivation of the present work arises from the great interest of the automotive industry to develop coatings on the piston surface that can enhance the efficiency of the engine. However, the surface of the automotive pistons nowadays possesses an optimized complex shape with a combination of convex, concave, and tilted surfaces. This design is intended to accomplish a higher air circulation in the piston surface for better mixing with the fuel, achieving a higher engine efficiency. However, applying a suitable thermal sprayed coating on the required surfaces on the piston presents a technical challenge $[25,26]$. As shown in detail by the authors in [8], there are changes in the 
coating microstructure along the piston's surface due to the alternated shape changes, combined with the necessity to perform the spraying under an angle. The focus of this work was on the alteration in microstructure and thermal properties due to variations in spray angle and spray distance while spraying on the surface of the piston with complex geometry. Two different top coat systems were produced by APS and SPS on flat-surfaced coupons and pistons for light-duty diesel engines. The resulting coating had the microstructure and porosity evaluated via image analysis and the thermal properties evaluated with laser flash analysis and finite element modeling.

\section{Materials and Methods}

\subsection{Materials and Equipment}

Two types of coatings were used in this work. The feedstocks were decided based on the applicability on the combustion chamber of diesel engines to achieve higher engine efficiency and on the previous research carried on both spraying methods. In the first, a lamellar microstructure was produced by APS using the F4-MB gun from Oerlikon Metco (Stockholm, Sweden). The feedstock used was NiCoCrAlY (AMPERIT 410) for the bond coat. The top coat was produced from a blend of DySZ (10 wt.\% $\mathrm{Dy}_{2} \mathrm{O}_{3}$ stabilized $\mathrm{ZrO}_{2}$ ) powder and polymer particles. For the APS top coat, the parameters were based on previous studies from Curry et al. [27] and shown in Table 1. The polymer porosity former was used to increase the porosity of the coatings $[27,28]$ due to the indication that the higher porosity could be favorable for the engine efficiency of the diesel engine [8]. The blend of DySZ and polymer was the only available powder with polyester. Since the DySZ and the yttria-stabilized zirconia (YSZ) powders behave in similar way, the microstructure results would not be influenced [29]. The second coating comprised of a dense high velocity air fuel (HVAF) bond coat and a columnar SPS top coat. For producing the bond coat, an M3 gun from Uniquecoat Technologies was used, and a NiCoCrAlY feedstock (AMDRY 386), whereas for producing the top coat, an Axial III gun from Mettech Corp and yttria-stabilized zirconia (YSZ) suspension in ethanol were employed. The solid load of the YSZ was $25 \mathrm{wt.} \%$ (Treibacher). The SPS top coat parameters were adopted from previous work [8] and shown in Table 1. Coupons of aluminum alloy (eutectic $\mathrm{Al}-12 \% \mathrm{Si}$ ) material and dimensions $25.4 \mathrm{~mm}$ in diameter and $6 \mathrm{~mm}$ in thickness were used as substrate specimens. The same coatings were deposited on real pistons used in light-duty diesel engines of the same material with a diameter of around $82 \mathrm{~mm}[8,9]$. Plates of Hastelloy-X with $25 \times 25 \times 1.54 \mathrm{~mm}^{3}$ were used for thermal properties measurement by Laser Flash Analysis.

Table 1. Top coat parameters.

\begin{tabular}{ccccccccc}
\hline Coating & Current (A) & Voltage (V) & $\begin{array}{c}\text { Gas Flow } \\
(\mathrm{L} / \mathbf{m i n})\end{array}$ & Power $(\mathbf{k W})$ & $\begin{array}{c}\text { Feed } \\
(\mathrm{mL} / \mathbf{m i n})\end{array}$ & $\begin{array}{c}\text { Argon } \\
(\mathrm{L} / \mathrm{min})\end{array}$ & $\begin{array}{c}\text { Hydrogen } \\
(\mathrm{L} / \mathrm{min})\end{array}$ & $\begin{array}{c}\text { Nitrogen } \\
(\mathrm{L} / \mathrm{min})\end{array}$ \\
\hline APS & 530 & 60 & 14 & 32 & - & 30 & 8 & - \\
SPS & 200 & - & - & 100 & 42 & 86 & 57 & 57 \\
\hline
\end{tabular}

\subsection{Coating Production}

The flat-surfaced coupons were sprayed using a rotating fixture with the substrates orthogonal to the spray direction. Prior spraying, the substrates were grit blasted with alumina grit to surface roughness $\left(R_{\mathrm{a}}\right)$ of around $3 \mu \mathrm{m}$. After grit blasting, a bond coat layer was sprayed, followed by the top coats using the materials specified in the previous section. The spray distance for spraying the topcoats on coupons was $140 \mathrm{~mm}$ for the APS process and $100 \mathrm{~mm}$ for the SPS process. The plasma parameters were kept constant for the coupon and piston.

The piston spraying was performed with a different methodology due to the piston shape and to the irregular spray area. Pistons were positioned on a turntable, and the spraying was undertaken with the tilted spray gun executing a transversal movement over the surface of the piston, as presented in Figure 1. For analysis purposes, the piston surface was divided into five different regions, Figure 1 
and Table 2, labeled according to the shape and spray distance, measured from the center of the respective region.

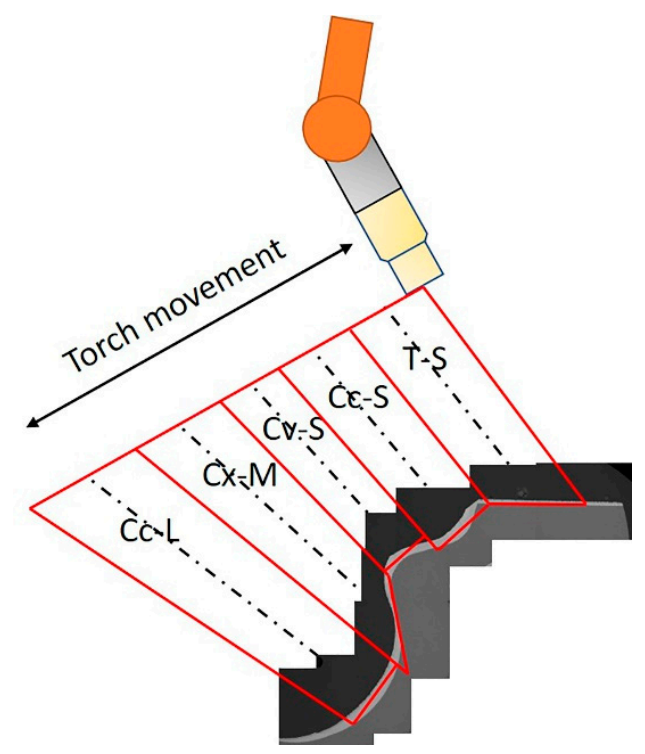

Figure 1. Different regions for the piston spraying.

Table 2. Nomenclature of the different regions of the piston spraying.

\begin{tabular}{ccc}
\hline Nomenclature & Shape & Spray Distance \\
\hline Cc-L & Concave & Long \\
Cx-M & Complex & Medium \\
Cv-S & Convex & Short \\
Cc-S & Concave & Short \\
T-S & Tilted & Short \\
\hline
\end{tabular}

Using the same methodology as in [8], the coating was not applied on the whole piston surface but on the piston sections that are most affected by the heat during the combustion cycle [30]. This area starts from the bottom of the piston wall on region $\mathrm{Cc}-\mathrm{L}$, going up over the most severe spot on region $\mathrm{Cx}-\mathrm{M} / \mathrm{Cv}-\mathrm{S}$ up until the top surface of the piston on region T-S.

The robot parameters were kept the same for APS and SPS; in this way, the spray angle was unchanged along with the different spraying techniques. The spray angles on different piston regions were measured between the gun center axis and a tangent to the bond coat in the middle of the piston region, with the aid of micrographs. The spray distances were measured between the nozzle exit and the substrate in the center of the region, in the beginning, and at the end of the robot program. Based on these values and the transversal gun path, the spray distances were calculated, as shown in Table 3, in association with the spray angle. The difference in the spray distances between the different spraying techniques is due to the shorter spray distance generally used for SPS as compared to the longer spray distance in APS $[16,17,22]$. 
Table 3. Spray angle and distance for the coupon and along the different regions of the piston.

\begin{tabular}{cccc}
\hline \multirow{2}{*}{ Sample/Region } & Spray Angle $\left(^{\circ}\right)$ & \multicolumn{2}{c}{ Spray Distance $(\mathbf{m m})$} \\
\cline { 3 - 4 } & & APS & SPS \\
\hline Coupon & 90 & 140 & 100 \\
Cc-L & 92 & 160 & 114 \\
Cx-M & 35 & 129 & 92 \\
Cv-S & 94 & 101 & 72 \\
Cc-S & 86 & 104 & 74 \\
T-S & 128 & 111 & 79 \\
\hline
\end{tabular}

\subsection{Microstructure Characterization}

The sprayed coupons and the different regions of the piston underwent metallographic preparation. Two different mountings under vacuum were performed, the first one with a low-viscosity epoxy resin to avoid problems with the preparation and a second one with a high-viscosity resin to have an adequate sample for the analysis. Using a Struers Secotom 10 precision cutting machine (Struers Inc., Cleveland, $\mathrm{OH}, \mathrm{USA}$ ), the samples were sectioned and then grinded and polished with a Buehler Power Pro 5000 equipment (Buehler, Waukegan, IL, USA). For the piston cutting, the method used in the previous study by Uczak de Goes et al. [8] was applied to section the piston across the desirable area.

The thickness measurements of the coatings on the sprayed coupon and along the different regions of the piston were carried out on cross-sectioned micrographs using a scanning electron microscope (SEM) TM 3000 from HITACHI (Hong Kong, China). Fifteen measurements were taken along the cross-section of $300 \times$ magnification images, and the average of the measurements was taken as the final value.

For coating's porosity measurement, a two-magnification image analysis procedure was employed, as described in [18]. For the coarse porosity, 1000× magnification was used to evaluate the pores larger than $2 \mu \mathrm{m}^{2}$. For the fine porosity, 5000× magnification was used, measuring the pores smaller than $2 \mu \mathrm{m}^{2}$. Each layer was measured ten times along the different regions for the lower and the higher magnifications, and the average of both was combined, resulting in the total porosity.

\section{Column Characterization}

The measurement of the column orientation employed cross-section images abiding by the different piston regions. In each region, five angles were measured on $300 \times$ magnification micrographs. The angle was measured between the columns centerline and the bond coat surface, as shown in Figure 2. The final angle was calculated as the average of fifteen angles measured in three different micrographs in each of the piston regions.

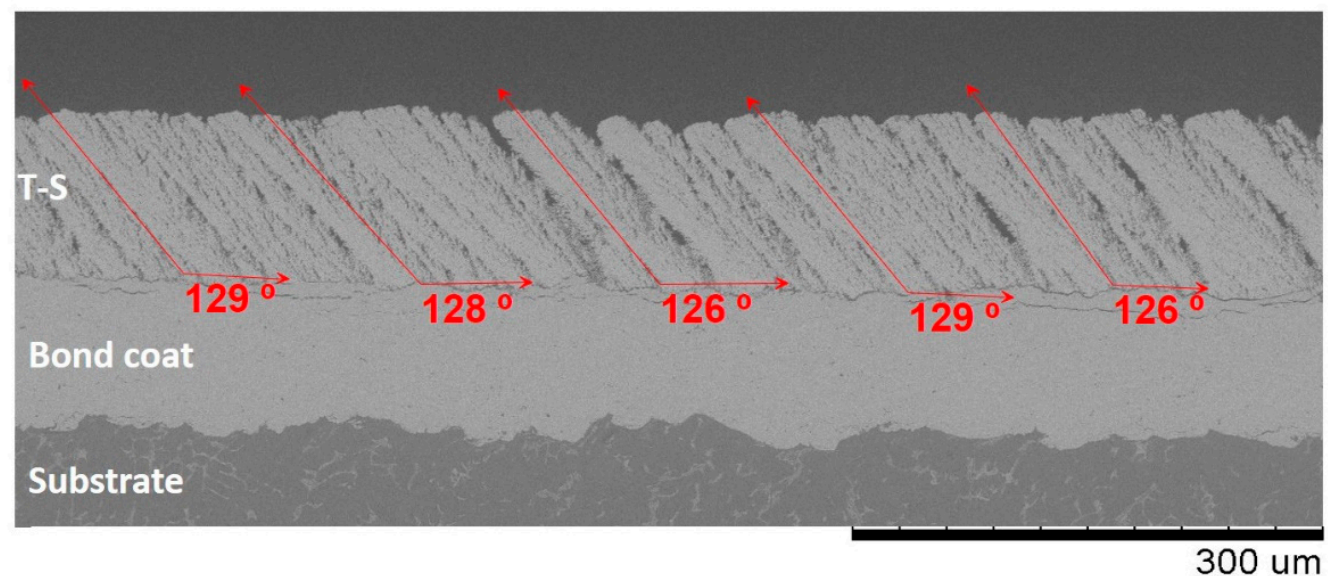

Figure 2. Column orientation on region T-S. 
The determination of the column density was undertaken using the following procedure. The $300 \times$ magnification micrographs taken previously for the column orientation were used. In these images, a fixed-length straight line of length $800 \mu \mathrm{m}$ was drawn along the middle of the top coat and parallel to the bond coat surface and the inter columnar spacings that intercept the line counted as shown in Figure 3. With this information, Equation (1) was used, and the column density was determined.

$$
\text { Column density }\left(\frac{\text { Columns }}{\mathrm{mm}}\right)=\frac{\text { Number of inter columnar spacing }}{\text { Length of the line }}
$$

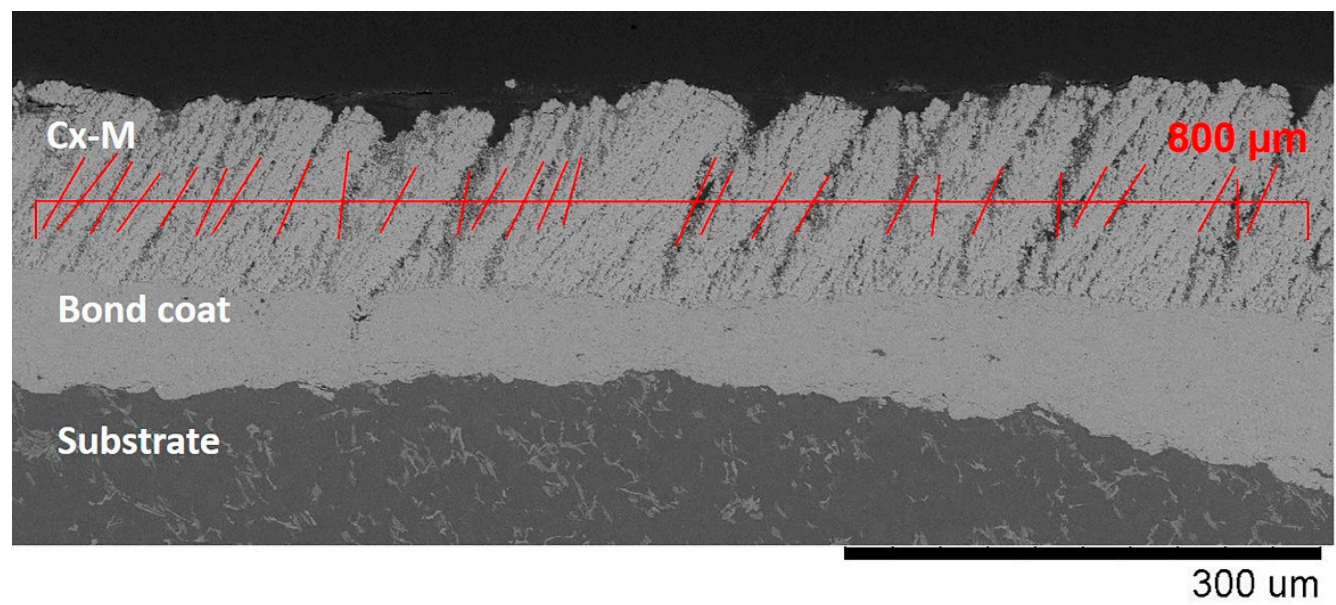

Figure 3. Column density in region Cx-M.

The final column density was taken as an average of three different images in each of the piston regions.

\subsection{Thermal Properties (Experimental)}

The thermal properties of the TBCs sprayed on coupons were experimentally evaluated by Laser Flash Analysis (LFA) using a Netzsch Laser Flash Apparatus (LFA) 427 (Netzsch, Selb, Germany). For this test, the sprayed samples were dimensioned by water jet cutting to round coupons of $10 \mathrm{~mm}$ in diameter. The samples were then placed in the LFA (with a temperature-controlled environment), where a laser pulse heated the back of the sample. This pulse generated a heat flux through the layers, detected on the front side of the sample with an infrared (IR) detector. With the information collected by the IR detector, the thermal diffusivity was determined. The complete description of this measurement procedure was presented elsewhere [31].

With the thermal diffusivity results, the thermal conductivity was calculated according to Equation (2).

$$
\lambda=\alpha \times C_{\mathrm{p}} \times \rho
$$

where $\lambda$ is the thermal conductivity $(\mathrm{W} /(\mathrm{mK})), \alpha$ is the thermal diffusivity $\left(\mathrm{mm}^{2} / \mathrm{s}\right), C_{\mathrm{p}}$ is the specific heat capacity $(\mathrm{J} /(\mathrm{g} \mathrm{K}))$ and $\rho$ is the coating density $\left(\mathrm{g} / \mathrm{cm}^{3}\right)$.

Since during the combustion cycle, a considerable amount of heat is generated on the coating's surface, the dissipation of this heat is essential. Therefore, thermal effusivity expressing specifically heat dissipation, is introduced, presenting a more suitable thermal property for the internal combustion engine applications $[8,32]$. Based on the thermal conductivity, the thermal effusivity was calculated according to Equation (3).

$$
e=\sqrt{\lambda \times \rho \times C_{\mathrm{p}}}
$$

where $e$ is the thermal effusivity $\left(\mathrm{J} /\left(\mathrm{s}^{1 / 2} \mathrm{~m}^{2} \cdot \mathrm{K}\right)\right)$. 
The coating density was calculated with Equation (4) based on the fully dense TBC and the measured porosity of the coatings.

$$
\rho=\left(\frac{100-\text { total porosity }(\%)}{100}\right) \times(\text { density of the fully dense coating })
$$

The density of the fully dense coating was taken from literature as $6.1 \mathrm{~g} / \mathrm{cm}^{3}$ [33]. The specific heat capacity value here was used from previous differential scanning calorimetry measurements reported in [33]. The properties were assumed identical for both coatings.

\subsection{Thermal Properties (Simulation)}

Due to the difficulties in preparing specimens from pistons for the experimental measurements of thermal properties of the coatings, e.g., LFA, an alternative is to calculate them by modeling using the object-oriented finite element (OOF) method [34-36]. A method developed by Ganvir et al. [34] using two different magnifications was used. The images used in the modeling were the same as in the porosity evaluation, presented in Section 2.3. At each magnification, five images were used in the respective piston region and coupon.

In this evaluation, the first step was the calculation of the thermal conductivity of the coatings with a higher magnification (5000x). This was done by using the binary image generated for the porosity measurement. The binary images contained only pores (in white color) and top coat material (in black color).

The next step was carried out in the software OOF2 (version 2.1.16) where the image was divided into two pixel groups for the two different pixel colors. For the white pixels, a pore material group, and for the black pixels, a top coat material group was assigned. The thermal conductivities of the groups were also defined, employing $2.5 \mathrm{~W} /(\mathrm{m} \cdot \mathrm{K})$ the bulk YSZ thermal conductivity for the top coat material group, and $0.025 \mathrm{~W} /(\mathrm{m} \cdot \mathrm{K})$ for the pore material group, corresponding to the thermal conductivity of the atmospheric air [34]. After this, an adaptive meshing procedure available in OOF2 was used to create a finite mesh based on the image features and colors.

Afterward, the boundary conditions were employed in OOF2 with a temperature difference of $200{ }^{\circ} \mathrm{C}$ between the top and bottom boundaries, assuming that the left and right boundaries were insulated. With these conditions, the result was the heat flux across the cross-section area of the coating and based on this, the thermal conductivity was calculated, solving Fourier's Law shown in Equation (5).

$$
Q=-\lambda \times A \times \frac{\Delta T}{\Delta x}
$$

where $Q$ is the heat flux $(\mathrm{W}), \lambda$ is the thermal conductivity, $A\left(\mathrm{~m}^{2}\right)$ is the area parallel to the top and bottom boundaries of the cross-section. $\Delta T(\mathrm{~K})$ is the temperature difference between the top and bottom boundaries, and $\Delta x(\mathrm{~m})$ is the thickness of the coating in the flow direction.

Subsequently, for the calculation of the thermal conductivity at the lower magnification $(1000 \times)$, in the same way, as in the higher magnification, the images were imported into OOF2 and divided into two different pixel groups. To define the thermal conductivity of the pixel groups, instead of using the bulk thermal conductivity for the top coat material group, the 5000× magnification thermal conductivity was incorporated while the thermal conductivity of air was kept the same. Afterward, in a similar way as for the 5000× magnification, the finite element mesh was created, and the thermal conductivity was estimated based on the setting of the boundary conditions. The resulting thermal conductivity was used for the coating, as it took into consideration all the features of the coatings.

With the thermal conductivity results established, the thermal effusivity was calculated following the procedure shown in Section 2.4. 


\section{Results and Discussions}

\subsection{Microstructure}

The microstructure of all coatings was investigated with SEM and the significant features of the coatings are shown in Figures 4-6.
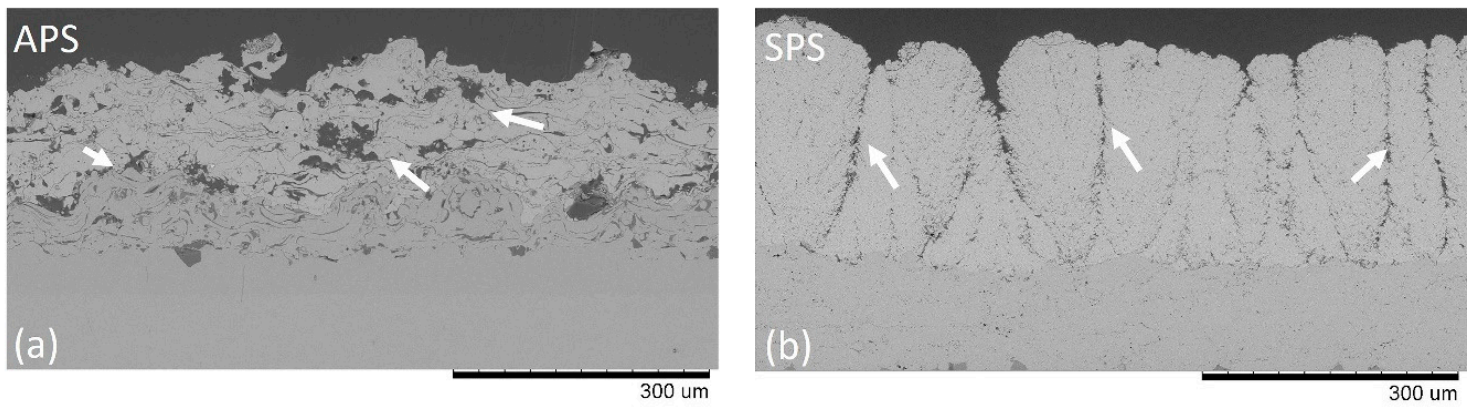

Figure 4. SEM cross-section images of the APS and SPS coatings sprayed on coupons, respectively (a) and (b).

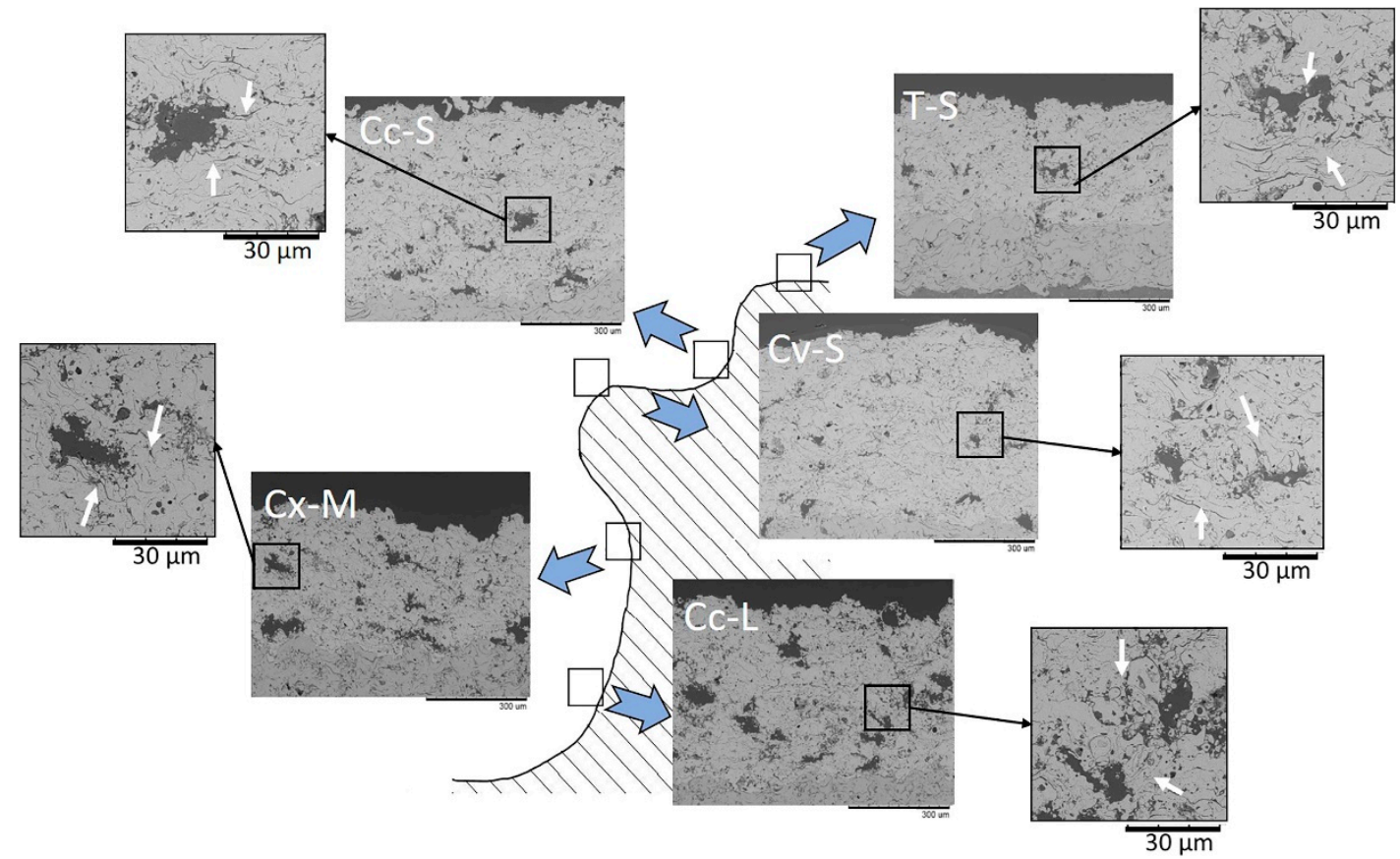

Figure 5. SEM cross-section images of the APS coating along the different regions of the piston.

Figure 4 shows the APS and SPS coatings sprayed on the flat-surfaced coupon, the target microstructures to achieve on the pistons. Figure $4 \mathrm{a}$ presents the characteristic APS lamellar microstructure of a porosity former coating with large pores along with the coating and fragmented cracks, indicated with the white arrows, as also reported in [37]. Figure $4 b$ presents the specific SPS coating with a variation of columns, porosity, and column gaps, signaled with white arrows, along with the entire sample.

Cross-section microstructures of coatings applied on the different regions of the piston are shown in Figures 5 and 6; each position is indicated by the nomenclature showed in Section 2.2. (Figure 1 and Table 3). In Figure 5, it can be observed as in the coupon, the typical microstructure of a porosity former coating with the presence of the large pores distributed evenly and small fragmented cracks, indicated with white arrows in the higher magnification pictures. 


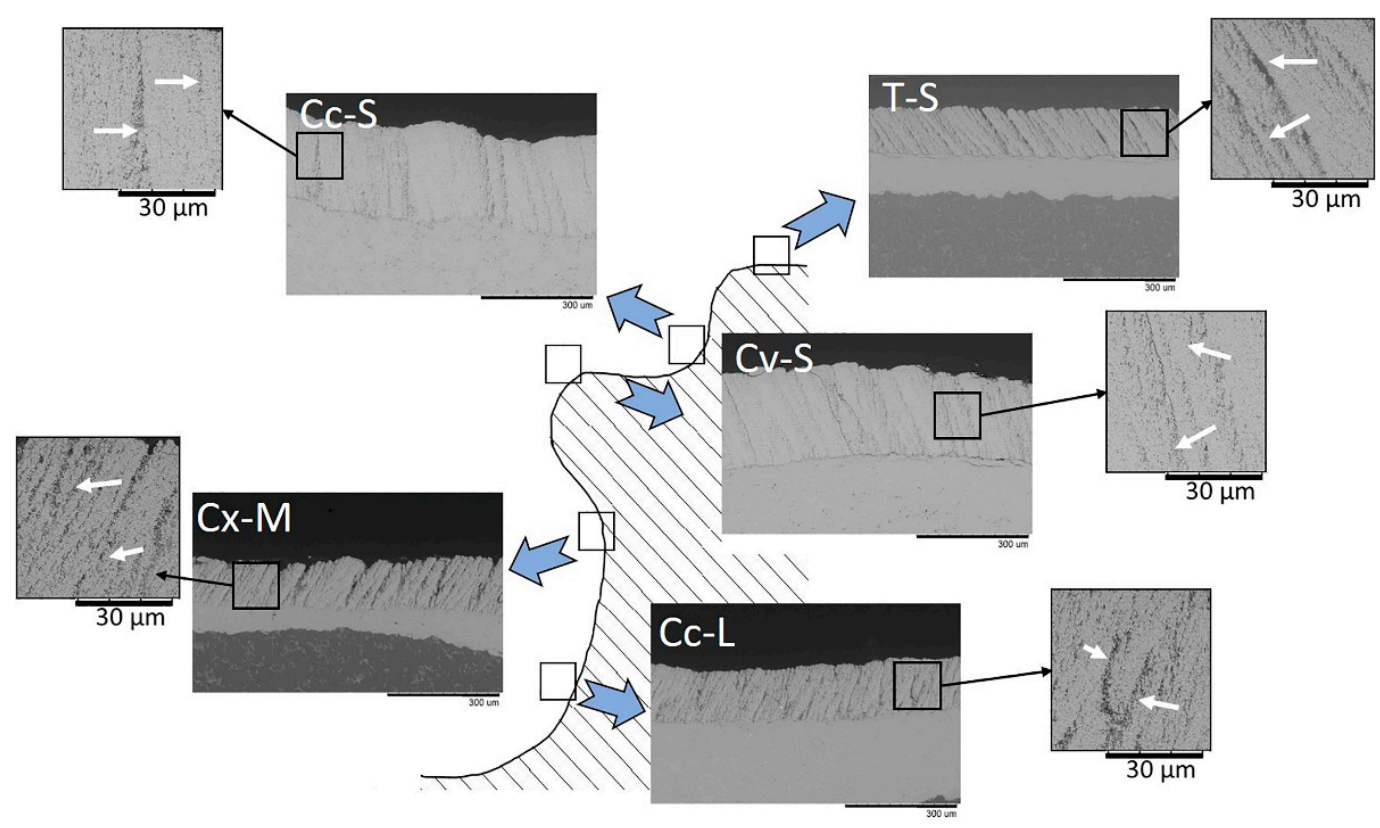

Figure 6. SEM cross-section images of the SPS coating along the different regions of the piston.

The pore network in the APS coating allows the infiltration of the combustion gases during the high pressure of the compression stroke. After the compression stroke during the exhaust stroke, the cracks can expand due to the fast release of the pressure, and this could lead to the delamination of the coating [3-7].

In Figure 6, the standard microstructure for the SPS coating is shown consisting of columns, porosity, and column gaps varying along the different regions of the piston. Microstructural deviations were observed, with different column structure (column gaps, column angle and column density) from columnar to a mixture of columnar and dense vertically cracked (DVS) microstructure. The column gaps, indicated with the white arrows in the higher magnification pictures, can give the coating an increased strain tolerance due to the widening of the columns under the high oscillating temperature inside the diesel engine, granting the coating a greater lifetime [38].

Thickness and porosity differences can be noted in both Figures 5 and 6 . The differences arise from the influence of the spray angle and spray distance on the particle temperature and normal velocity. These parameters influence the deposition mechanism by modifying the deposition efficiency and the bonding within the deposited particles, characteristics further discussed in Sections 3.2 and 3.3.

\subsection{Thickness}

Coating thickness variation along the different regions of the piston is shown in Figure 7. For the APS coating, the maximum thicknesses were found in the regions $\mathrm{Cv}-\mathrm{S}$ and $\mathrm{Cc}-\mathrm{S}$. This was expected due to the spray angles close to $90^{\circ}$, and the shorter spray distance. Due to the changes in the spray distance, Cc-L showed the 3rd highest thickness, followed by T-S with a lower thickness due to a lower spray angle combined with the substrate shape and the lowest thickness for $\mathrm{Cx}-\mathrm{M}$ with a lower spray angle and a medium spray distance.

The spray angle influences the normal velocity of the particles at impact, i.e., the maximum normal velocity is reached at a $90^{\circ}$ spray angle [10]. With a lower spray angle, the normal velocity drops and simultaneously the deposition rate due to the rebounding of the particles that have not enough energy to deform and stick to the surface, as shown by Davis [12].

In plasma spraying, shorter spray distance allows higher particle temperature and the deposition of the coatings with a higher particle velocity at impact, increasing the deposition efficiency of the coating, as shown in region Cv-S and Cc-S [11,12]. In the case of region Cc-L, the higher thickness can 
be due to the lower particle deformation associated with the longer spray distance that leads to colder particles and decreased impact velocity.

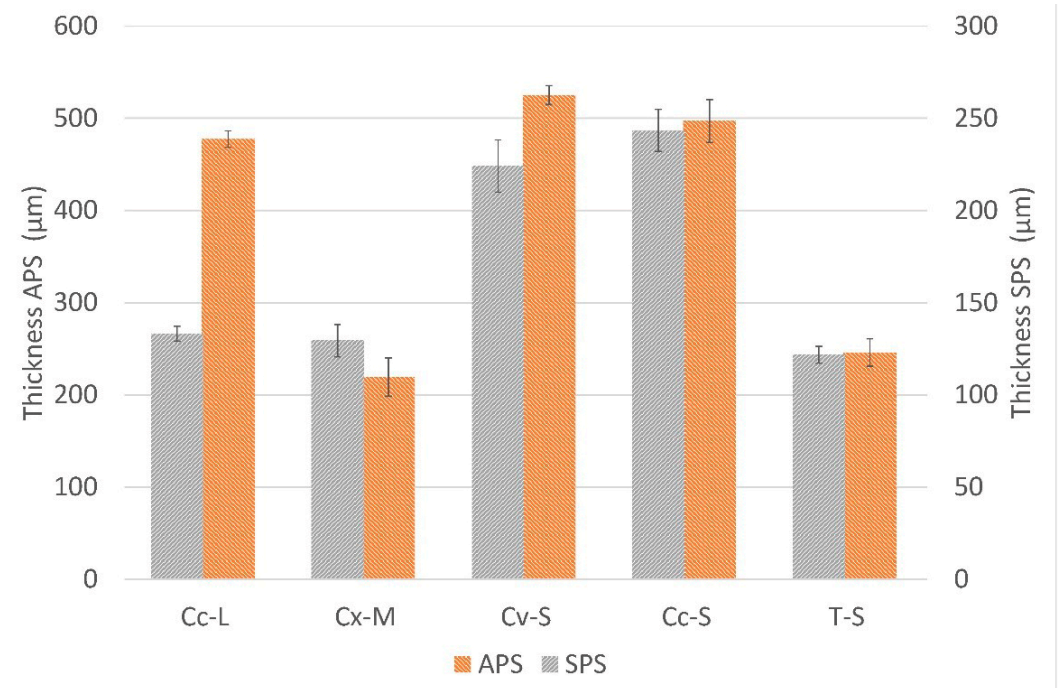

Figure 7. Thickness variation along the different regions of the piston for the APS and SPS coating.

When spraying, depending upon the conditions, the rebounding of particles on the surface can affect the coating formation [39]. On the concave region, the rebounding of small particles combined with the reverse flow of the plasma streamlines could lead to the respraying of the rebounded particles. This respraying might contribute to higher coating thickness [40].

For the SPS coating, due to a different coating formation mechanism, the thickness variations between the different regions of the pistons are much smaller than for the APS [41]. The thickness in different regions was changed, but the maximum thicknesses were also found in the piston regions where shorter spray distance was used, region $\mathrm{C}_{\mathrm{c}-\mathrm{S}}$ and $\mathrm{Cv}-\mathrm{S}$. These were followed by region $\mathrm{Cc}_{\mathrm{C}} \mathrm{L}$ because of the longer spray distance and regions Cx-M and T-S, likely because of the spray distance combined with the substrate shape.

Similar to APS coating, the spray distance and spray angle influenced the coating formation in the SPS process. This was because, with a longer spray distance, there is a lower normal particle velocity and a lower particle temperature at impact. In this way, more particles are re-solidified before impact, therefore, most of the particles cannot adhere $[18,21,24]$. This effect is more pronounced in the SPS coating than APS, thus creating the difference in thickness trend in the region $\mathrm{Cc}-\mathrm{L}$ as compared to other regions.

The substrate shape influenced the SPS coating thickness similarly to the APS coating, but due to the different formation mechanism, the influence of the different plasma streamlines is more pronounced on the SPS coating. The region T-S presents the lowest thickness, likely because there is no reverse flow due to the tilted substrate shape, and the smaller particles are dragged away with the plasma flow [23].

Relating the importance of the thickness with the diesel engine application, a study of the most affected area in the piston surface during the combustion cycle was performed by Uchihara et al. [30]. Combining simulation and tests, the optimal area for insulation was predicted and is corresponding to the area from region Cc-S to region Cx-M. As shown in Figure 7, for both coatings in this area, there is good coverage, showing the applicability of the coatings and the method.

The different thicknesses along the surface of the piston can influence the final shape of the piston's surface but also create functionality issues, i.e., the thicker coating can hit (mechanical contact) the cylinder head leading to damages. As shown by Li et al. [26], there is a significant impact on the combustion due to changes in the geometry of the piston surface. To avoid these problems, the pistons 
can be machined before spraying, to remove material from the regions where a thicker coating is expected to be deposited and, thus, not interfering with the desired final shape of the piston.

\subsection{Porosity}

The porosity of the coatings on the regions along the piston is presented in Figure 8 for the APS and SPS coatings.

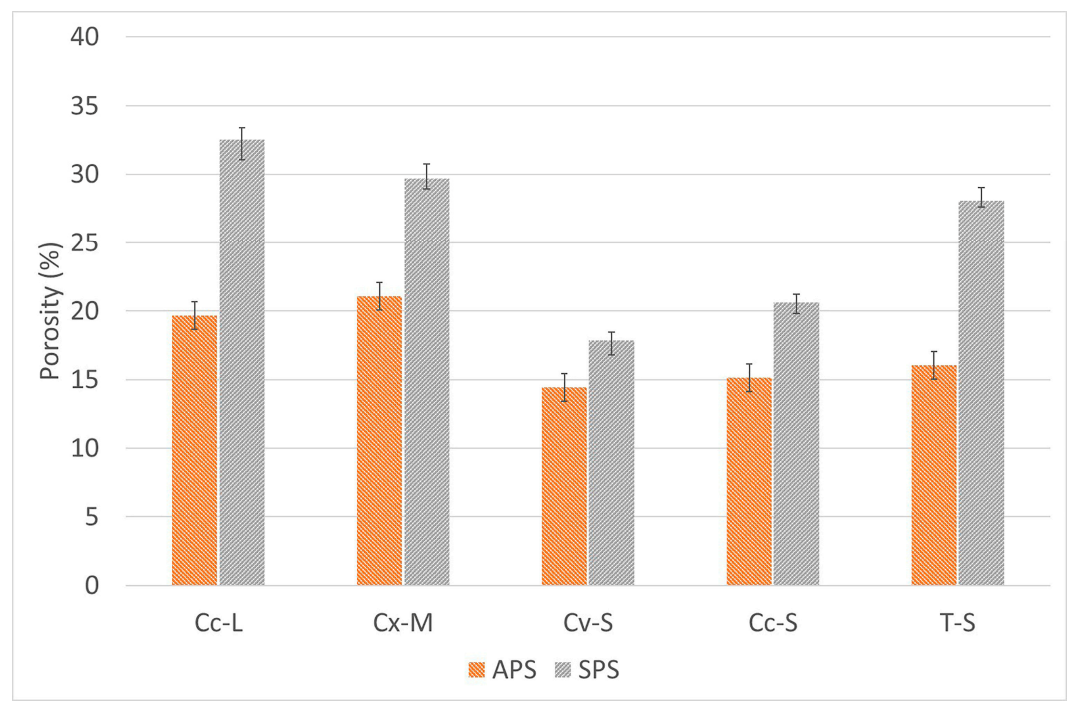

Figure 8. APS and SPS porosity in different regions of the piston.

For the APS coatings, the lowest porosity was found on region $\mathrm{Cv}-\mathrm{S}$ and $\mathrm{Cc}-\mathrm{S}$, where the spray angle is close to normal, and there is a shorter spray distance. This was followed by region T-S due to a short spray distance combined with a lower angle of spraying. The highest porosity values were found in regions $\mathrm{Cc}-\mathrm{L}$ and $\mathrm{Cx}-\mathrm{M}$. The higher porosity could be due to the longer spray distance. The spray distance similarly influences the porosity as the influence on the thickness of the coating. With a longer spray distance, the particle loses temperature and decelerates. Under these circumstances, the particle would not form a proper splat, not completely overlapping the previous splats affecting the cohesion of the coating and producing a higher porosity coating [42,43].

The spray angle influences porosity in the same way as it influences the thickness of the coatings, i.e., through the momentum of the particles. With a spray angle lower or higher than $90^{\circ}$, a decrease of the normal particle velocity would be observed, resulting in a weaker bonding and higher porosity, a behavior also observed in previous works [44-46].

The influence of the substrate shape can be correlated with the effect of the plasma streamlines on the thickness [40]. Due to the concave profile of the substrate, the small particles are exposed to reverse flow, and the rebounded particles could be resprayed, leading to a higher thickness [40]. These resprayed particles would have a weak bond, producing a higher porosity coating, as shown in the region Cc-L.

In the SPS coatings deposited along the different regions of the piston, the lowest porosity was found on the region Cv-S, followed by region Cc-S and T-S; this could be related to the short spray distance and the substrate shape. The highest porosities were found on regions with the longer spray distance Cx-M and Cc-L due to the effect of the longer spray distance combined with the substrate shape.

The spray distance influences porosity comparably to the influence on the thickness; with a longer spray distance, the velocity and temperature of the particles are lowered, promoting a deposition with a lower flattening, increasing the porosity, as seen in regions CC-L and Cx-M [15,47]. 
The substrate shape influences porosity, similarly, as it was proposed for the APS coatings, due to the plasma streamline [40]. The high porosity on the concave region Cc-L can be associated with the reverse flow plasma streamline combined with the rebound particles and the deficiency in cohesion within the coating.

The difference between the porosity trends along the different regions of the APS and SPS coatings arise from the different deposition process. In the SPS process, the smaller particles combined with a longer spray distance leads to the deceleration and lower temperature of the particles. Leading to cohesion problems and producing a higher porosity coating.

The porosity is a crucial feature of the coating's applied in engines due to the influence on the thermal properties but also because of the entrapment of the fuel during the combustion cycle. The entrapment of the fuel affects the engine efficiency causing late combustion and prolonging the combustion cycle. To avoid this problem, a coating without open porosity would be needed, or a sealing layer should be applied [7-9].

An optimal porosity, comparable to the porosity values of the flat-surfaced coupon of $25 \% \pm 2 \%$ and $18 \% \pm 2 \%$ respectively for the APS and SPS coatings, should be presented along with the different piston regions. Due to the difficulties in spraying on complex shapes combined with the study from Uchihara et al. [30], the area from region Cc-S to region Cx-M should be prioritized an optimized porosity.

\subsection{Column Structure}

Along the different regions in the sprayed piston with SPS coating, the columns exhibited an orientation parallel to the torch axis during spraying, aligning in this way with the spray angle, as shown by the trendline in Figure 9. Similar behavior was observed previously by [22] who sprayed on different substrate shapes and observed the tendency of the columns to be parallel with the torch axis in different substrate shapes.

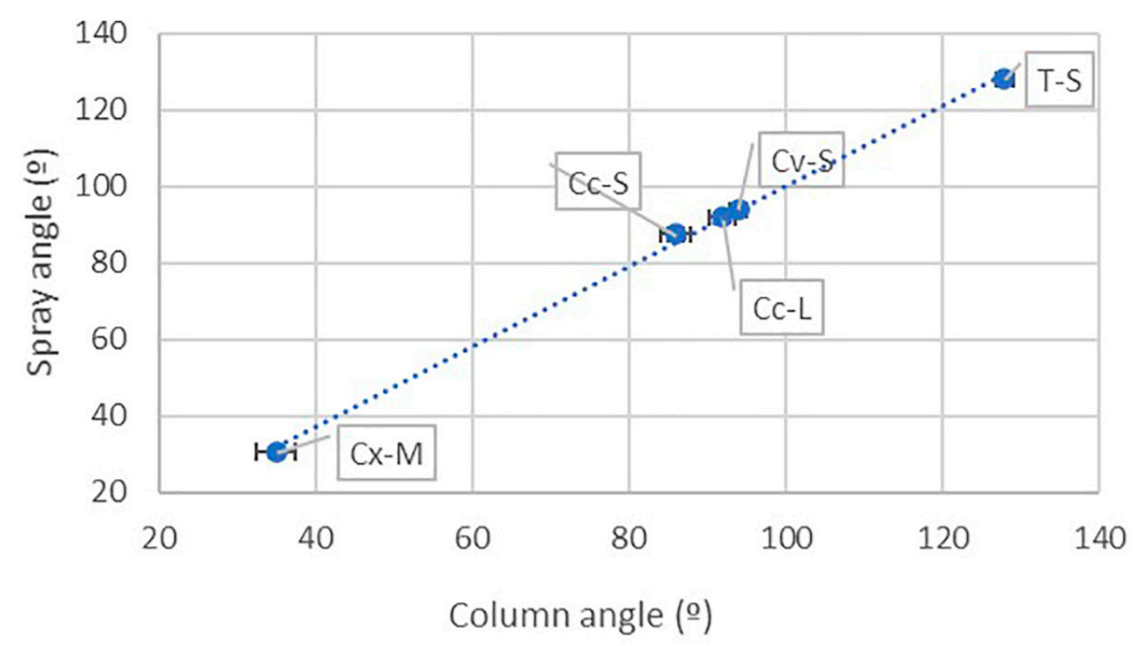

Figure 9. Column angle variation along with different spray angles.

In SPS, the coating formation is determined by the particle momentum and the plasma drag. The particles are influenced by the plasma drag; in this way, the coating is deposited at shallow angles on the asperities of the surface. With a longer spray distance, there is a reduction in the momentum of the particles. Based on the lower momentum, the particles are more easily dragged within the plasma drag and would favor the formation of columns, as shown in Figure 10 and previously observed by $[16,20]$. 


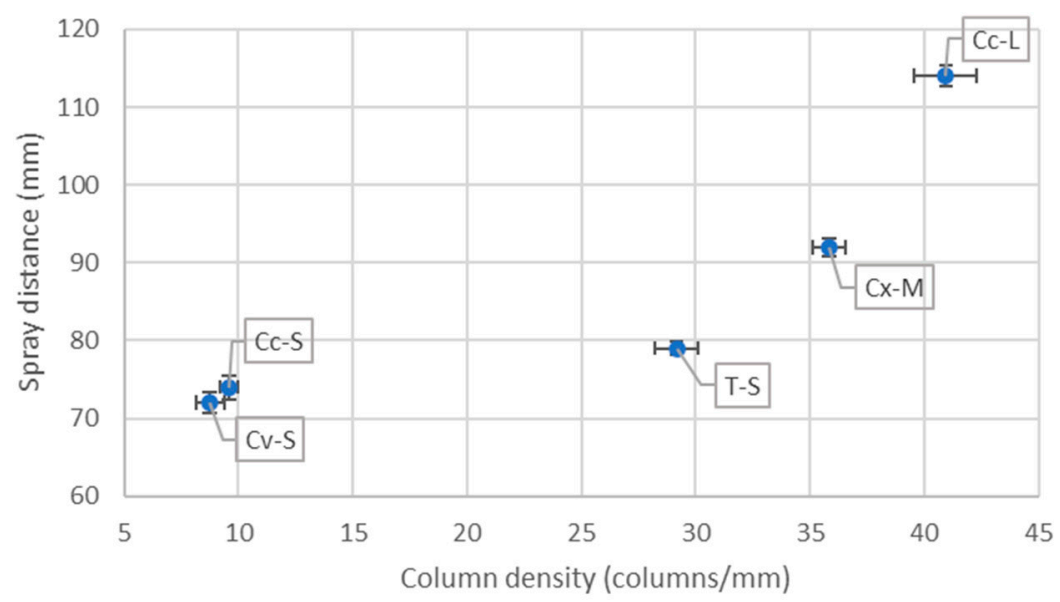

Figure 10. Column density variation along with different spray distances.

In the context of diesel engines, as shown earlier in this section, more column gaps can increase the strain tolerance of the coatings. This feature could lead to distinct lifetimes along the different regions. Considering this, regions with a lower number of column gaps (lower column density) during the fluctuation of the temperature inside of the diesel engine would be most affected due to a lower strain tolerance [38]. Due to this, the desirable microstructure should possess an average column density, close to the flat-surface coupons that possessed around 12 columns/mm.

\subsection{Thermal Properties}

The experimental and modeled thermal properties results are shown in Figures 11 and 12 against the porosity for the different regions of the piston and for the coupon. In Figure 11 for the APS coating, the thermal properties show an increase when the porosity decreased. The porosity impacts due to the lower thermal properties of the gas inside the pore as compared to the TBC material and the porosity boundaries that contribute to the phonon scattering, leading to a lower thermal conductivity, similar behavior to that shown in previous research $[48,49]$.

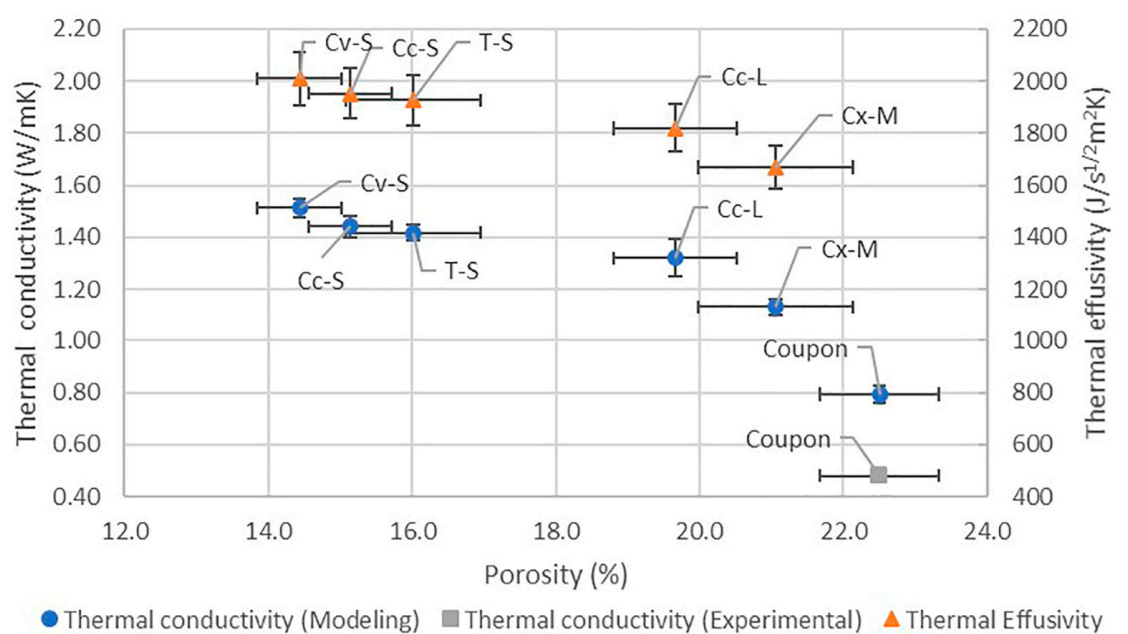

Figure 11. Thermal properties of the APS coupon compared in different regions of the piston. 


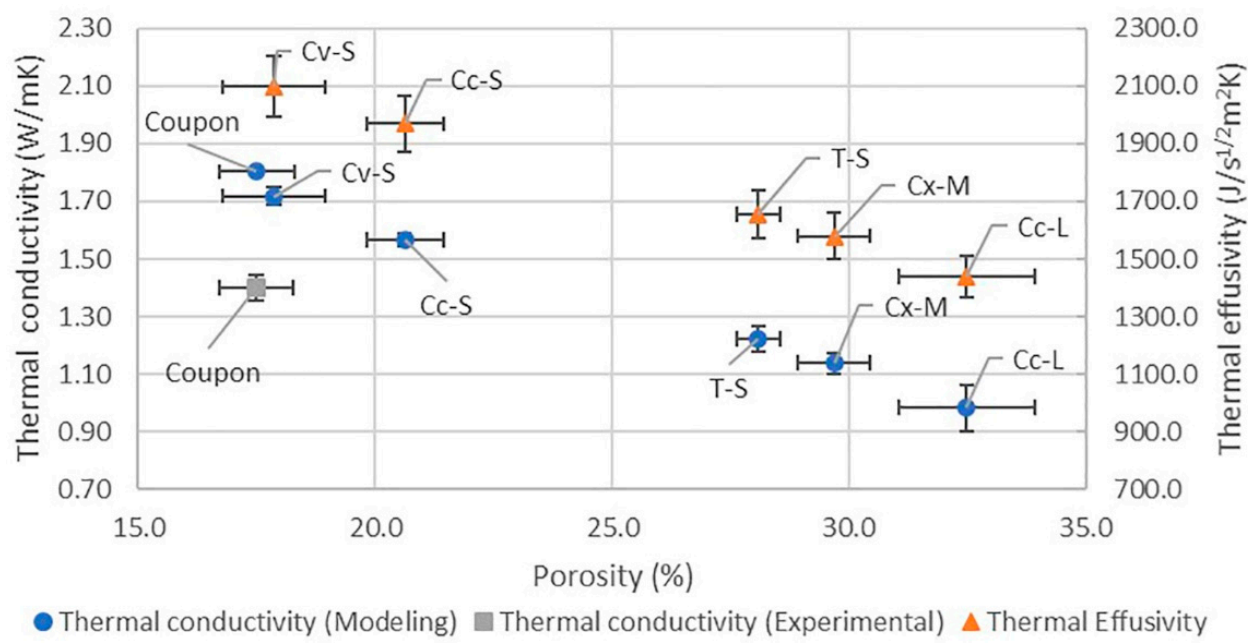

Figure 12. Thermal properties of the SPS coupon compared in different regions of the piston.

The SPS coating showed the same trend as the APS with an increase of the thermal properties with the porosity decrease, as shown in Figure 12 and previously concluded in [34,50-52].

Comparing the value of the thermal conductivity determined by modeling with that determined by experimental measurements on coupons, in both types of coatings, the thermal conductivities for modeling as compared to the experimental measurements are higher, as shown in Figures 11 and 12. The main explanation of this result is related to the limitation of the microstructure characterization by image analysis. In the coating, several features affect the thermal conductivity, e.g., pores, cracks, and column gaps $[34,50,53]$. These features, summed up as total porosity, are significantly influencing the measurement of the thermal conductivity. In the experimental method, even the minimal features, i.e., nanoscale pores/cracks, which cannot be captured and counted by image analysis for total porosity measurement, are acting as thermal barriers. In the modeling procedure, these very fine features are not included, but only the total porosity measured by image analysis, leading to higher values for thermal conductivity. An additional constraint is due to the 2D geometry used by the model that may not correspond to the heat flux present in a 3D microstructure, creating the difference between the experimental and the modeling procedures. Regardless of the variations, the thermal conductivity exhibited a good correlation between the experimental and modeled values, with deviations of results in similar limits as found by Ganvir et al. [34] and Gupta et al. [28]. The thermal conductivity measurements via modeling were not expected to have the exact values, but a trend was awaited.

For the application in diesel engines, improvements in engine efficiency were achieved with coatings with lower thermal conductivity and thermal effusivity, as shown previously by $[8,9]$. The differences in thermal properties were seen along with the piston due to the thermal spray process combined with the complex shape piston, as discussed in Section 3.1. The most desirable lower thermal conductivity and thermal effusivity should be similar to the flat-surfaced coupons and presented from region $\mathrm{Cc}-\mathrm{S}$ until region $\mathrm{Cx}-\mathrm{M}$ [30]. To achieve this, a fine-tuning of the spraying process should be done combining different spraying masks of the different piston regions and machining, but the initial results are positive.

\section{Conclusions}

This study presented and investigated light-duty diesel engine pistons and flat surface coupons sprayed with two thermal spray techniques for the top coat, APS and SPS. These coatings were characterized by scanning electron microscopy (SEM) using an image analysis technique to evaluate the thickness, porosity, and microstructures. The thermal properties (thermal conductivity and thermal effusivity) were determined for the regions of the piston by modeling and the flat-surfaced coupons measured by laser flash analysis and determined via modeling, for comparison. 
A strong effect of the spray angle and spray distance on the deposition features (particle temperature and normal velocity) was observed, leading to different microstructures and porosities along the different piston regions. It was also observed the substrate shape effect on the microstructure due to the deviations of the plasma streamlines along with the different surface shapes on the piston. The effect of these different elements was mainly seen in the SPS coatings due to the higher dependency on the particle trajectory, altering the column formation in terms of column angles and column density.

A good correlation between the experimental and modeled values for the coupon was found. Allowed with this a study of the different thermal properties along the different regions of the pistons and the flat-surfaced coupon, creating a connection between the real piston parts with complex geometry and the flat coupons.

The differences in microstructure and thermal properties were noted along with the piston, which is believed to interfere with the application of the TBCs in diesel engines. However, with the knowledge acquired in this detailed investigation, the coating formation can be better understood, and a microstructure, similar to the flat-surfaced coupons, along the different regions can be produced in the future, leading to the best conditions for the application of TBCs in diesel engines.

Author Contributions: Conceptualization, W.U.d.G., N.M., and M.G.; methodology, W.U.d.G., N.M., and M.G.; software, W.U.d.G.; formal analysis, W.U.d.G., N.M., and M.G.; investigation, W.U.d.G.; resources, N.M. and M.G.; writing_-original draft preparation, W.U.d.G.; writing—review and editing, W.U.d.G., N.M., and M.G.; supervision, N.M. and M.G.; funding acquisition, N.M. All authors have read and agreed to the published version of the manuscript.

Funding: This research was funded by the Swedish Energy Agency, part of the FFI Energy and Environment Program.

Acknowledgments: The authors would like to acknowledge Chamara Kumara and Joop Somhorst for the helpful discussions. Authors also would like to thank Stefan Björklund from University West, Trollhättan, for the help in the spraying the samples.

Conflicts of Interest: The authors declare no conflict of interest.

\section{References}

1. Miller, R.A. Thermal barrier coatings for aircraft engines: History and directions. J. Therm. Spray Technol. 1997, 6, 35. [CrossRef]

2. Sirignano, W.A.; Liu, F. Performance Increases for Gas-Turbine Engines Through Combustion Inside the Turbine. J. Propuls. Power 1999, 15, 111-118. [CrossRef]

3. Tree, D.R.; Oren, D.C.; Yonushonis, T.M.; Wiczynski, P.D. Experimental Measurements on the Effect of Insulated Pistons on Engine Performance and Heat Transfer; SAE International: Warrendale, PA, USA, 1996.

4. Kamo, R.; Mavinahally, N.S.; Kamo, L.; Bryzik, W.; Schwartz, E.E. Injection Characteristics that Improve Performance of Ceramic Coated Diesel Engines; SAE International: Warrendale, PA, USA, 1999.

5. Mendera, K.Z. Effectiveness of Plasma Sprayed Coatings for Engine Combustion Chamber; SAE International: Warrendale, PA, USA, 2000.

6. Hejwowski, T. Comparative study of thermal barrier coatings for internal combustion engine. Vacuum 2010, 85, 610-616. [CrossRef]

7. Beardsley, M.B.; Happoldt, P.G.; Kelley, K.C.; Rejda, E.F.; Socie, D.F. Thermal Barrier Coatings For Low Emission, High Efficiency Diesel Engine Applications; SAE International: Warrendale, PA, USA, 1999.

8. Uczak de Goes, W.; Somhorst, J.; Markocsan, N.; Gupta, M.; Illkova, K. Suspension Plasma-Sprayed Thermal Barrier Coatings for Light-Duty Diesel Engines. J. Therm. Spray Technol. 2019, 28, 1674-1687. [CrossRef]

9. Somhorst, J.; Uczak De Goes, W.; Oevermann, M.; Bovo, M. Experimental Evaluation of Novel Thermal Barrier Coatings in a Single Cylinder Light Duty Diesel Engine; SAE International: Warrendale, PA, USA, 2019.

10. Montavon, G.; Sampath, S.; Berndt, C.C.; Herman, H.; Coddet, C. Effects of the spray angle on splat morphology during thermal spraying. Surf. Coat. Technol. 1997, 91, 107-115. [CrossRef]

11. Gupta, M.; Dwivedi, G.; Nylén, P.; Vackel, A.; Sampath, S. An Experimental Study of Microstructure-Property Relationships in Thermal Barrier Coatings. J. Therm. Spray Technol. 2013, 22, 659-670. [CrossRef]

12. Davis, J.R. Handbook of Thermal Spray Technology; ASM International: Cleveland, OH, USA, 2004; pp. 14-35. 
13. Pawlowski, L. Suspension and solution thermal spray coatings. Surf. Coat. Technol. 2009, 203, 2807-2829. [CrossRef]

14. Ganvir, A.; Joshi, S.; Markocsan, N.; Vassen, R. Tailoring columnar microstructure of axial suspension plasma sprayed TBCs for superior thermal shock performance. Mater. Des. 2018, 144, 192-208. [CrossRef]

15. Berghaus, J.O.; Bouaricha, S.; Legoux, J.; Moreau, C. Injection conditions and in-flight particle states in suspension plasma spraying of alumina and zirconia nano-ceramics. In Proceedings of the International Thermal Spray Conference, Basel, Switzerland, 2-4 May 2005; pp. 2-4.

16. VanEvery, K.; Krane, M.J.M.; Trice, R.W.; Wang, H.; Porter, W.; Besser, M.; Sordelet, D.; Ilavsky, J.; Almer, J. Column Formation in Suspension Plasma-Sprayed Coatings and Resultant Thermal Properties. J. Therm. Spray Technol. 2011, 20, 817-828. [CrossRef]

17. Kang, C.-W.; Ng, H.W.; Yu, M.-C. Imaging Diagnostics Study on Obliquely Impacting Plasma-Sprayed Particles Near to the Substrate. J. Therm. Spray Technol. 2006, 15, 118-130. [CrossRef]

18. Ganvir, A.; Curry, N.; Björklund, S.; Markocsan, N.; Nylén, P. Characterization of Microstructure and Thermal Properties of YSZ Coatings Obtained by Axial Suspension Plasma Spraying (ASPS). J. Therm. Spray Technol. 2015, 24, 1195-1204. [CrossRef]

19. Pourang, K.; Moreau, C.; Dolatabadi, A. Effect of Substrate and Its Shape on in-Flight Particle Characteristics in Suspension Plasma Spraying. J. Therm. Spray Technol. 2016, 25, 44-54. [CrossRef]

20. Ganvir, A.; Calinas, R.F.; Markocsan, N.; Curry, N.; Joshi, S. Experimental visualization of microstructure evolution during suspension plasma spraying of thermal barrier coatings. J. Eur. Ceram. Soc. 2019, 39, 470-481. [CrossRef]

21. Bernard, B.; Quet, A.; Bianchi, L.; Schick, V.; Joulia, A.; Malié, A.; Rémy, B. Effect of Suspension Plasma-Sprayed YSZ Columnar Microstructure and Bond Coat Surface Preparation on Thermal Barrier Coating Properties. J. Therm. Spray Technol. 2017, 26, 1025-1037. [CrossRef]

22. Caio, F.; Moreau, C. Influence of Substrate Shape and Roughness on Coating Microstructure in Suspension Plasma Spray. Coatings 2019, 9, 746. [CrossRef]

23. Kang, C.W.; Ng, H.W.; Yu, S.C.M. Comparative Study of Plasma Spray Flow Fields and Particle Behavior Near to Flat Inclined Substrates. Plasma Chem. Plasma Process. 2006, 26, 149-175. [CrossRef]

24. Fukumoto, M.; Nishioka, E.; Nishiyama, T. New criterion for splashing in flattening of thermal sprayed particles onto flat substrate surface. Surf. Coat. Technol. 2002, 161, 103-110. [CrossRef]

25. Jadidi, M.; Mousavi, M.; Moghtadernejad, S.; Dolatabadi, A. A Three-Dimensional Analysis of the Suspension Plasma Spray Impinging on a Flat Substrate. J. Therm. Spray Technol. 2015, 24, 11-23. [CrossRef]

26. Li, J.; Yang, W.M.; An, H.; Maghbouli, A.; Chou, S.K. Effects of piston bowl geometry on combustion and emission characteristics of biodiesel fueled diesel engines. Fuel 2014, 120, 66-73. [CrossRef]

27. Curry, N.; Markocsan, N.; Li, X.-H.; Tricoire, A.; Dorfman, M. Next Generation Thermal Barrier Coatings for the Gas Turbine Industry. J. Therm. Spray Technol. 2011, 20, 108-115. [CrossRef]

28. Gupta, M.; Curry, N.; Nylén, P.; Markocsan, N.; Vaßen, R. Design of next generation thermal barrier coatings-Experiments and modelling. Surf. Coat. Technol. 2013, 220, 20-26. [CrossRef]

29. Curry, N.; Janikowski, W.; Pala, Z.; Vilémová, M.; Markocsan, N. Impact of Impurity Content on the Sintering Resistance and Phase Stability of Dysprosia- and Yttria-Stabilized Zirconia Thermal Barrier Coatings. J. Therm. Spray Technol. 2014, 23, 160-169. [CrossRef]

30. Uchihara, K.; Ishii, M.; Nakajima, H.; Wakisaka, Y. A Study on Reducing Cooling loss in a Partially Insulated Piston for Diesel Engine; SAE International: Warrendale, PA, USA, 2018.

31. Mahade, S.; Curry, N.; Björklund, S.; Markocsan, N.; Nylén, P. Thermal conductivity and thermal cyclic fatigue of multilayered Gd2Zr2O7/YSZ thermal barrier coatings processed by suspension plasma spray. Surf. Coat. Technol. 2015, 283, 329-336. [CrossRef]

32. Bergman, T.L.; DeWitt, D.P.; Incropera, F.; Lavine, A.S. Fundamentals of Heat and Mass Transfer; John Wiley \& Sons: Hoboken, NJ, USA, 2011; Volume 997, ISBN 978-0-470-50197-9.

33. Mahade, S.; Curry, N.; Björklund, S.; Markocsan, N.; Nylén, P.; Vaßen, R. Functional performance of Gd2Zr2O7/YSZ multi-layered thermal barrier coatings deposited by suspension plasma spray. Surf. Coat. Technol. 2017, 318, 208-216. [CrossRef]

34. Ganvir, A.; Kumara, C.; Gupta, M.; Nylen, P. Thermal Conductivity in Suspension Sprayed Thermal Barrier Coatings: Modeling and Experiments. J. Therm. Spray Technol. 2017, 26, 71-82. [CrossRef] 
35. Langer, S.; Fuller, E.; Carter, W. OOF: An Image-Based Finite-Element Analysis of Material Microstructures. Comput. Sci. Eng. 2001, 3, 15-23. [CrossRef]

36. Guo, X.; Hu, B.; Wei, C.; Sun, J.G.; Jung, Y.-G.; Li, L.; Knapp, J.; Zhang, J. Image-based multi-scale simulation and experimental validation of thermal conductivity of lanthanum zirconate. Int. J. Heat Mass Transf. 2016, $100,34$.

37. Curry, N.; Markocsan, N.; Östergren, L.; Li, X.-H.; Dorfman, M. Evaluation of the Lifetime and Thermal Conductivity of Dysprosia-Stabilized Thermal Barrier Coating Systems. J. Therm. Spray Technol. 2013, 22, 864-872. [CrossRef]

38. Lughi, V.; Tolpygo, V.K.; Clarke, D.R. Microstructural aspects of the sintering of thermal barrier coatings. Mater. Sci. Eng. A 2004, 368, 212-221. [CrossRef]

39. Pawlowski, L. The Science and Engineering of Thermal Spray Coatings; John Wiley \& Sons: Hoboken, NJ, USA, 2008; ISBN 0-471-95253-2.

40. Ba, T.; Kang, C.W.; Ng, H.W. Numerical Study of the Plasma Flow Field and Particle In-flight Behavior with the Obstruction of a Curved Substrate. J. Therm. Spray Technol. 2009, 18, 858. [CrossRef]

41. Fauchais, P.; Heberlein, J.; Boulos, M. Thermal Spray Fundamentals. From Powder to Part; Springer: New York, NY, USA, 2013.

42. Kucuk, A.; Berndt, C.C.; Senturk, U.; Lima, R.S.; Lima, C.R.C. Influence of plasma spray parameters on mechanical properties of yttria stabilized zirconia coatings. I: Four point bend test. Mater. Sci. Eng. A 2000, 284, 29-40. [CrossRef]

43. Ramachandran, C.S.; Balasubramanian, V.; Ananthapadmanabhan, P.V. Multiobjective Optimization of Atmospheric Plasma Spray Process Parameters to Deposit Yttria-Stabilized Zirconia Coatings Using Response Surface Methodology. J. Therm. Spray Technol. 2011, 20, 590-607. [CrossRef]

44. Leigh, S.H.; Berndt, C.C. Evaluation of off-angle thermal spray. Surf. Coat. Technol. 1997, 89, $213-224$. [CrossRef]

45. Chen, Y.; Tan, Y.; Tessarini, S.; Sampath, S. Integrated Study of APS YSZ Coatings with Different Spray Angle. J. Therm. Spray Technol. 2012, 22. [CrossRef]

46. Ilavsky, J.; Allen, A.; Long, G.; Krueger, S.; Berndt, C.; Herman, H. Influence of Spray Angle on the Pore and Crack Microstructure of Plasma-Sprayed Deposits. J. Am. Ceram. Soc. 2005, 80, 733-742. [CrossRef]

47. Tesar, T.; Musalek, R.; Medricky, J.; Cizek, J. On growth of suspension plasma-sprayed coatings deposited by high-enthalpy plasma torch. Surf. Coat. Technol. 2019, 371, 333-343. [CrossRef]

48. Golosnoy, I.O.; Cipitria, A.; Clyne, T.W. Heat Transfer Through Plasma-Sprayed Thermal Barrier Coatings in Gas Turbines: A Review of Recent Work. J. Therm. Spray Technol. 2009, 18, 809-821. [CrossRef]

49. Kulkarni, A.; Vaidya, A.; Goland, A.; Sampath, S.; Herman, H. Processing effects on porosity-property correlations in plasma sprayed yttria-stabilized zirconia coatings. Mater. Sci. Eng. A 2003, 359, 100-111. [CrossRef]

50. Kaßner, H.; Stuke, A.; Rödig, M.; Vaßen, R.; Stöver, D. Influence of porosity on thermal conductivity and sintering in suspension plasma sprayed thermal barrier coatings. Ceram. Eng. Sci. Proc. 2009, 29, 147-158.

51. Ekberg, J.; Ganvir, A.; Klement, U.; Creci, S.; Nordstierna, L. The Influence of Heat Treatments on the Porosity of Suspension Plasma-Sprayed Yttria-Stabilized Zirconia Coatings. J. Therm. Spray Technol. 2018, 27, 391-401. [CrossRef]

52. Ganvir, A.; Markocsan, N.; Joshi, S.V. Influence of Isothermal Heat Treatment on Porosity and Crystallite Size in Axial Suspension Plasma Sprayed Thermal Barrier Coatings for Gas Turbine Applications. Coatings 2016, 7, 4. [CrossRef]

53. Markocsan, N.; Nylén, P.; Wigren, J.; Li, X.-H. Low Thermal Conductivity Coatings for Gas Turbine Applications. J. Therm. Spray Technol. 2007, 16, 498-505. [CrossRef]

(C) 2020 by the authors. Licensee MDPI, Basel, Switzerland. This article is an open access article distributed under the terms and conditions of the Creative Commons Attribution (CC BY) license (http://creativecommons.org/licenses/by/4.0/). 